\title{
Price Signals and Uncertainty in Commercial Real Estate Transactions
}

\section{Matthew Cypher, S. McKay Price, Spenser Robinson \& Michael J. Seiler}

The Journal of Real Estate Finance and Economics

ISSN 0895-5638

$J$ Real Estate Finan Econ

DOI 10.1007/s11146-017-9617-0

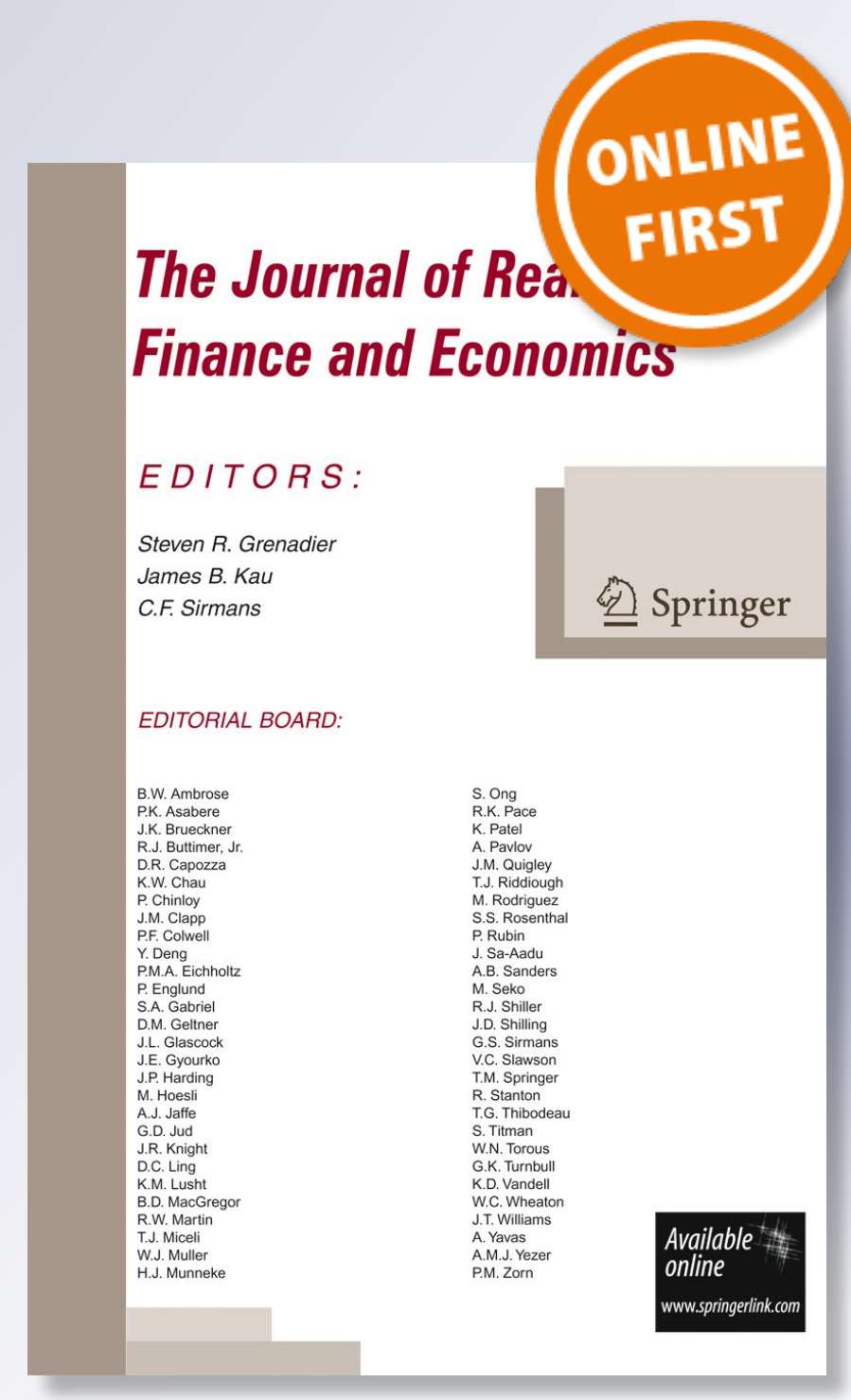

照 Springer 
Your article is protected by copyright and all rights are held exclusively by Springer Science+Business Media, LLC. This e-offprint is for personal use only and shall not be selfarchived in electronic repositories. If you wish to self-archive your article, please use the accepted manuscript version for posting on your own website. You may further deposit the accepted manuscript version in any repository, provided it is only made publicly available 12 months after official publication or later and provided acknowledgement is given to the original source of publication and a link is inserted to the published article on Springer's website. The link must be accompanied by the following text: "The final publication is available at link.springer.com". 


\title{
Price Signals and Uncertainty in Commercial Real Estate Transactions
}

\author{
Matthew Cypher ${ }^{1}$ • S. McKay Price ${ }^{2}$ (D) \\ Spenser Robinson ${ }^{3} \cdot$ Michael J. Seiler $^{4}$
}

(C) Springer Science+Business Media, LLC 2017

\begin{abstract}
Using a sample of CCIM designees and candidates in an experimental setting, this study examines the impact of broker signaling in commercial real estate transactions. It also explores the effect of certainty of closure in commercial real estate transactions. Findings suggest brokers are able to influence transaction pricing. Moreover, detailed analysis reveals that when a signal is above a reference point implied by previous transactions, the strength of the signal matters; privately communicated signals from reliable sources have significantly greater impact than signals which are made widely available. Additionally, we find an approximately $10 \%$ premium in transactions with lower certainty of closure than one with high certainty. The latter result varies by transactional participant type; owner/developers require a larger premium than institutional sellers.
\end{abstract}

Keywords Commercial Real Estate $\cdot$ Broker $\cdot$ Signaling $\cdot$ Uncertainty $\cdot$ Execution Risk

Michael J. Seiler

Michael.Seiler@mason.wm.edu

Matthew Cypher

Matthew.Cypher@georgetown.edu

S. McKay Price

smp210@lehigh.edu

Spenser Robinson

s.robinson@cmich.edu

1 McDonough School of Business, Georgetown University, Washington, DC, USA

2 Perella Department of Finance, Lehigh University, Bethlehem, PA 18015, USA

3 Central Michigan University, Mt Pleasant, MI, USA

4 Department of Finance, Raymond A. Mason School of Business, P.O. Box 8795, Williamsburg, VA 23187-8795, USA 
JEL Classification $\mathrm{G} 11 \cdot \mathrm{G} 24 \cdot$ and R33

\section{Introduction}

Commercial real estate (CRE) brokers are an integral part of the CRE transaction process. Yet, few studies exist which examine the potential impact of brokers on CRE transactions (Devaney and Scofield 2013; Garmaise and Moskowitz 2004; Hardin et al. 2009; Ling et al. 2016). This is, in part, due to data limitations. Broker advice and behavior cannot be directly observed in transactional price data (Bokhari and Geltner 2011; Gatzlaff and Liu 2013). The negotiation process, broker guidance, and how the likelihood of transaction completion (i.e., certainty of close) affects such signals are unobserved. To capture these pieces of information an experiment is required.

The only empirical analysis of the impact of CRE brokers on property transactions, of which we are aware, is Ling et al. (2016). The authors examine whether information intermediaries (i.e., brokers) are able to attenuate behavioral biases associated with geographic proximity/distance. They find brokers generally make their clients worse off (e.g., increase the acquisition prices of buyers and decrease the disposition prices of sellers). The historical transactional data used in that paper does not isolate the mechanism by which brokers influence price (i.e., signaling). We conduct an experiment which holds constant geographic proximity and all other outside factors in order to isolate the effect of broker signaling on commercial property pricing. We move the literature forward by specifically gauging the impact of a relationship with a broker, and the advice they provide, on CRE transactions. Using an experimental framework, this study analyzes the effect of signaling in CRE auctions along with the real estate illiquidity premium associated with certainty of close.

We also build upon Garmaise and Moskowitz (2004) who find strong evidence of information asymmetries in the private CRE market. They show that market participants attempt to mitigate information asymmetries by purchasing properties close to home, trading properties with long income histories, and avoiding transactions where the counterparty is an informed professional broker (i.e., brokers acting as principals trading in their own accounts). In discussing brokers acting as intermediaries the authors note that "buyers cannot rely on brokers to provide unbiased information" (p.410.) However, here too the CRE transactional data are not refined enough to examine broker guidance and execution risk. In an experimental setting we are able to isolate these aspects of CRE transactions while controlling for other potential means of overcoming information asymmetries by holding all else constant in the experimental design.

Our experiment is conducted on a sample of Certified Commercial Investment Member (CCIM) designees and candidates. These professionals possess above average knowledge in the CRE field as evidenced by their CCIM designation or candidacy and fall under what Garmaise and Moskowitz (2004) describe as well informed agents. ${ }^{1}$ Several recent behavioral publications use students as subjects. However, Haigh and List (2005) show clear differences in the behavior of student

\footnotetext{
${ }^{1}$ To be eligible for the CCIM designation a person must take a series of advanced courses, pass a full-day exam, and document substantial commercial real estate experience.
} 
participants vis-a-vis professional participants. This experiment demonstrates strong practical implications due to the professional, highly trained, and therefore, highly relevant nature of the subjects.

First, the experiment assesses responses from CCIM participants, asked to act as prospective buyers, to broker communicated information regarding a likely sale price. The scenario evaluates whether a signaling effect is present. Second, the experiment differentiates between a weak public signal and a strong private signal, permitting examination of differences in signal strength and reliability. Finally, the paper examines transactional execution risk measured in a real estate specific manner-the illiquidity premium in a certainty of close assessment. In addition, demographic data provides insight into differences between seller types.

Altogether, the evidence suggests that broker signals can affect pricing outcomes. We find that buyers tend to bid at or near the prices suggested to them by CRE brokers. Further, we show that broker reputation and the relationships they cultivate with prospective buyers are important. Buyers are more strongly influenced by privately communicated signals from trusted brokers than by readily available market information, particularly when the private signal conveys a price above a reference point implied by recent transactions of similar product. In the latter case, broker influence increases transaction prices by nearly $10 \%$, which far exceeds the cost of utilizing the intermediary. We also provide evidence that certainty of transaction completion is a nontrivial consideration. To compensate for the risk of a failed transaction, sellers require a price premium of roughly $10 \%$ from a buyer who is less likely to complete the transaction compared to a buyer who is highly likely to complete the transaction. When segmented by seller type, we find that owner/developers tend to be more sensitive to execution risk than institutional sellers.

The remainder of the paper includes a review of the literature and a discussion of the research design and hypotheses. This is followed by an outline of the treatment process and the analytical methods used to test the hypotheses. We then discuss the results and follow with concluding remarks.

\section{Literature Review}

In a survey of major institutional investors, lack of reliable valuation data and liquidity risk are reported as the top two main risks of investing in CRE (Dhar and Goetzmann 2005). We examine both of these components in our experimental framework and first discuss the literature on brokerage below. We then incorporate a discussion of the literature on liquidity and price as they relate to the certainty of transaction closure.

The literature on residential real estate brokerage is expansive. Studies range from examining barriers to entry in the brokerage business (Hsieh and Moretti 2003), to how hard brokers work (Benjamin et al. 2004; Goodwin et al. 2012), to potential conflicts of interest when brokers act as principals (Bian et al. 2017; Kadiyali et al. 2014) or dual agents (Han and Hong 2016; Johnson et al. 2015), to how commissions rates are determined (Shy 2012; Wiley et al. 2014). Many other brokerage topics have been explored in the residential real estate setting as well, often with conflicting results. For example, Munneke and Yavas (2001) theoretically model the differences in various commission structures and empirically show no difference in sale price and selling time 
across different brokerage compensation contracts, while Benefield et al. (2011) find higher sale prices and shorter selling time for limited service contracts relative to full service agreements, and Barwick et al. (2016) show that lower commission rates result in lower sale prices and longer selling time. Other studies find that residential brokers generally have no independent effect on home prices (Bernheim and Meer 2008; Elder et al. 2000).

Elder et al. (1999) consider the role of the residential broker in the search process and show that brokers increase buyer search intensity and reduce search time. Hendel et al. (2009) evaluate home sales using a brokerage platform versus a for-sale-by-owner approach and find the latter is less effective in terms of probability of transaction completion and sale time. Additionally, recent work finds that external agents enjoy superior selling ability when compared to owners acting as their own agents (Munneke et al. 2011).

Brastow et al. (2012) show that when a listing broker has specialized market knowledge, indicated by residential listing activity within a geographic area, they are more likely to sell homes at a premium. Turnbull and Dombrow (2007) also provide evidence that agents with particular expertise achieve better outcomes for their clients; those who specialize in listing (buying) property obtain higher (lower) sale prices. Levitt and Syverson (2008) argue that tremendous information asymmetry exists in real estate markets, and they demonstrate that agents are often better informed about the value of the house and the state of the local housing market than the clients who hire them. Moreover, seller confidence in a broker's abilities appears to be important as Daneshvary and Clauretie (2013) show that changing agents leads to less bargaining power, lower selling prices, and increased time on the market in residential transactions.

While the above mentioned literature informs our work, we do not include an exhaustive review of the residential real estate brokerage literature given (i) its size, and (ii) the extent to which the residential theoretical and empirical work applies in a CRE setting is unclear. ${ }^{2}$ Commercial markets differ from residential markets in meaningful ways. For example, the assets are more complex, transaction sizes are much larger, value determinants differ, decisions are typically investment-driven rather than consumption-driven, and transaction participants (i.e., buyers, sellers, brokers) are sophisticated. Consequently, a CRE broker's role may differ somewhat from that of residential brokers. Devaney and Scofield (2013) argue that commercial real estate markets have less information transparency than other common investment asset classes, which encourages the use of intermediaries during asset acquisition and disposal.

Altogether, brokerage in the CRE setting is less understood. Commercial brokers are often viewed as incorporating no more than basic information to value CRE properties (An et al. 2015). Hardin et al. (2009) show the presence of a broker provides no statistically significant impact on price in their investigation of multifamily income producing properties in Atlanta and Phoenix. They argue that brokers do not systematically influence prices in this CRE segment. Johnson et al. (2007) outline a relation between price and marketing time where a longer market time may lead to a lower price. This literature relates to our study as the broker may be motivated to transact a property more quickly, influencing the perception of broker guidance. Along

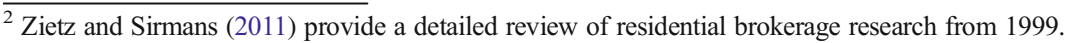


the same lines, Korngold (2011) argues that brokers are more incentivized to close quickly than to maximize sale price. Since the brokers often earn up to $3 \%$ of the sale price as a commission, the marginal increase in sale price may not be worth the additional risk, time, and/or marketing expenditure. ${ }^{3}$ He further argues that given this disincentive, brokers should not be considered fiduciaries. ${ }^{4}$

In contrast, D'Lima (2016) presents a theoretical framework for structuring broker compensation contracts, in a manner that is markedly different from residential brokerage fee arrangements, which would properly incentivize commercial brokers to add value by seeking the highest possible sale price. He further presents a sample of contracts from a major commercial real estate broker that is consistent with the theoretical prediction. Using a survey of fund managers and acquisition professionals, McAllister et al. (2008) conclude that institutional investors are aware of potential brokerage incentive issues and still manage to navigate through them. Further, they point to the need for brokers to establish personal relationships and trust with institutional buyers, given the limited market and prospect of repeat business, which helps align incentives of brokers with those of their clients. In other words, reputational concerns are nontrivial for CRE brokers.

Garmaise and Moskowitz (2004) find evidence that information asymmetry in CRE markets is high and buyers attempt to mitigate the information gap through purchasing nearby properties or those with long income histories. Lambson et al. (2004) find evidence that out-of-state buyers of multifamily properties pay more than in-state buyers, further supporting the idea of substantial information asymmetry in CRE markets and potentially higher search costs. Similarly, Devaney and Scofield (2017) suggest that CRE brokers help mitigate information barriers for foreign investors buying property in New York City. Gatzlaff and Liu (2013) show that commercial properties without a list price tend to sell for higher prices than those with one. While such an information environment may provide opportunities for brokers to influence price, these studies lack the data necessary to investigate whether this is the case. Indeed, to the best of our knowledge the literature is silent on the matter. We fill this gap by examining what effect, if any, brokers can have on price when specifically attempting to influence price.

Another important aspect of CRE transactions that we capture in our experimental framework is execution risk. Devaney and Scofield (2015) note that, "buying and selling commercial real estate involves a process of exchange that occurs over an extended period and incurs risks and costs of a character and order that are different from many other investment assets" (p. 362). The private and disperse nature of the market for these heterogeneous assets leads to costly searches and asset illiquidity. Lin and Vandell (2007) contend that the uncertainty of the marketing process and corresponding sale times introduce biases into CRE pricing models which implicitly assume immediate execution. That is, returns can be biased upward and risks can be biased downward. Cheng et al. (2008) make a similar argument and develop a pricing model which accounts for marketing period risk and the underestimation of its effect on price. They find that their model helps explain risk premiums observed in CRE markets. Still, Scofield (2013) finds that senior level investment professionals

\footnotetext{
${ }^{3}$ The authors recognize that larger deals may use lower percentages and some brokers may work off fixed fees. No legal framework for fee structure exists.

${ }^{4}$ The issue of pricing is also examined in the residential sector by Beracha and Seiler (2014).
} 
persistently overestimate transaction efficiency and underestimate liquidity risk when acquiring and disposing of commercial properties.

Chinloy et al. (2013) argue that sellers and brokers may favor buyers with a higher likelihood of transaction completion. Bond et al. (2007) examine the role of selling period uncertainty and find that sellers with larger portfolios bear less transaction closure risk than those with only a few (i.e., less than 10) CRE assets. However, Lin et al. (2009) suggest that even large institutional investors must consider the illiquidity of the individual assets and cannot assume that its effect will be diversified away in the context of marketing period risk. Interestingly, Devaney and Scofield (2015) find evidence that transactions are closed more quickly, and thus with greater certainty, when institutional investors are involved.

We add to this literature by conducting an experiment that enables us to examine transaction participant behavior in the context of certainty of close. The experimental structure allows us to investigate the illiquidity premium associated with execution risk. We are also able to consider whether there are certainty of closure premium differences by seller type.

\section{Research Design and Hypotheses}

Every potential buyer and seller drawn from the CCIM sample begins with the same background information in the two experiments conducted. Detailed demographics showing percentages of CCIM respondents in Owner/Developer firms (52\%) are shown below. Although CCIM designees most commonly function as brokers, reports from senior CCIM executives interviewed suggest that a minimum of $50 \%$ of CCIM designees purchase CRE property for their own investment. ${ }^{5}$ All participants asked to act as buyers are provided with details about a desirable retail property and current market capitalization rates for similar properties. Given the desirable nature of the asset and no resource constraints, it is assumed that property acquisition (i.e., transaction closure) is the goal. Without any additional information, buyers would be rationally expected to bid at the observed capitalization (cap) rate for similarly situated properties. This experiment examines price movement relative to the additional information provided by brokers. Selling brokers communicate what they expect to be the winning bid to the buyers. In a signaling mechanism, buyers consider whether the new price information communicates true market value. To test for price signaling effects by selling brokers, the following hypotheses are generated.

Hypothesis 1 Information that the prospective sale price of the asset is above a reference point implied by recent transactions of similar product yields higher bid prices.

Hypothesis $1 b$ Information that the prospective sale price of the asset is below a reference point implied by recent transactions of similar product yields lower bid prices.

\footnotetext{
${ }^{5}$ Multiple authors of this paper have either held the CCIM designation or been affiliate members of CCIM chapters through industries like banking. The personal experiences of the authors also corroborate the evidence from interviews of CCIM leadership.
} 
Separate hypotheses for the ability to move price below or above comparable properties are tested. Presumably, greater percentages of buyers would be willing to purchase at a perceived bargain than risk overpaying. However, not all signals are of equal value. A signal provided to the broad market by a broker could be potentially dismissed as a broker trying to raise the price for their client, or even an agency conflict where they are maximizing their own potential commission. To test whether the strength of the signal affects the outcome, the experiment differentiates between a broker who communicates to all potential buyers and a broker who conveys a "whisper price." A whisper price is industry vernacular for quietly communicated and generally confidential information concerning the likely sale price or seller's pricing threshold (i.e., reservation price). In the relationship driven world of commercial real estate, a whisper price from a reliable source likely demonstrates greater signaling effects. The following hypotheses, again separated by over- versus under- the buyer's expected sale price, test the signal strength:

Hypothesis $2 a$ A broker whisper price from a reliable source that the prospective sale price of the asset is above a reference point implied by recent transactions of similar product yields a stronger price movement than identical broad market signals.

Hypothesis $2 b$ A broker whisper price from a reliable source that the prospective sale price of the asset is below a reference point implied by recent transactions of similar product yields a stronger price movement than identical broad market signals.

The first two sets of hypotheses explore overall broker capacity and value. That is, information asymmetry exists between buyer and seller and we examine whether brokers can effectively eliminate uncertainty by conveying to prospective bidders what price would need to be offered to successfully acquire the asset. The next hypothesis explores an additional aspect of uncertainty associated with CRE transactions, execution risk. The illiquidity of real estate is well established (Anglin and Gao 2011; Lin et al. 2009; Vandell 2007) and sellers and brokers know that there is cross-sectional variation in buyer propensity to close transactions (Chinloy et al. 2013). This part of the experiment tests how much more sellers would require from a buyer with lower certainty of close than one with high certainty of close. If the potential loss from a failed sale attempt is consequential (Lin and Vandell 2007), then a premium would likely be imposed on a buyer with greater execution risk.

Hypothesis 3 CRE sellers extract a premium from CRE buyers with greater execution risk.

Some sellers may require higher premiums than others to compensate for uncertainty associated with transaction closure. Demographic data enables us to test for differences in the size of the uncertainty premium required across seller types.

Hypothesis 4 Sensitivity to execution risk varies by CRE seller type. 


\section{Treatment Process and Analytical Method}

The experiment is administered to CCIM holders and candidates, yielding 490 valid participants to the first part of the experiment and 436 for the second. The experiment is sponsored by the CCIM Institute and is conducted through an internet portal to a group of CCIM holders and candidates. To help us better understand the composition of CCIMs in our sample every subject is asked to complete basic demographic information as well, with slightly lower completion rates of 394 and 384, respectively.

Figure 1 details the organizations in which the participants work. Owner/Developer companies are most heavily represented with the majority of the remaining participants working in advisory, consulting, investment, or similar roles. Figure 2 details the job function or titles of the respondents. Approximately half of the participants are decision makers such as President/CEO, CFO, Partner, etc. Those in advisory or consulting roles presumably influence decision making. The respondent characteristics suggest that participants are capable of making informed decisions relating to CRE asset acquisitions. As mentioned earlier, using a sample of industry professionals to examine in depth CRE research hypotheses improves reliability over student populations (Haigh and List 2005). To further highlight this point, Fig. 3 shows $85 \%-90 \%$ of participants have experience negotiating leases and have been involved in acquisitions and/or dispositions. We also note that while many CCIMs are typically employed as commercial brokers we are asking all participants to assume the role of buyer and/or seller in the experiments. CCIMs are realistic and relevant subjects for such a design because they regularly participate in transactions as buyers and sellers. Garmaise and Moskowitz (2004) state that, "brokers are quite active in [the CRE] market as principals" (p.409). In roughly 7\% of their sample of over 10,000 individual commercial property transactions, either the seller or the buyer is a broker acting as a principal for his own account. ${ }^{6}$

The behavioral design of the experiment is based on current best practices (Seiler 2014). To analyze the research questions, the first experiment is constructed such that the subject participates in a hypothetical auction process for a grocery anchored shopping center. Information is provided that the center is $97 \%$ leased, in a strong location, with existing leases at market rental rates. In short, every indication is provided that it is a desirable property with stabilized net operating income (NOI). Participants are told they have previously put forth an initial bid of $\$ 48,600,000$ which has moved them into the best and final round of bidding. The question provides information regarding current market transactions which are reported to trade at a $5.0 \%$ capitalization rate, or $\$ 52,000,000$, based on the provided NOI of $\$ 2,600,000$.

In the first treatment, the participant is informed that all bidders are provided "broker guidance," in a public manner. Each individual only receives one guidance number, but the experimental design randomly generates one of three potential guidance numbers for a given scenario. That is, we follow a between-subjects design. Assuming the expected price is $\$ 52,000,000$, the potential guidance is under expectations at $\$ 49,500,000$, at the expected price of $\$ 52,000,000$, or over expectations at $\$ 54,700,000$.

\footnotetext{
${ }^{6}$ In addition, we independently contacted large national brokerages, small boutique firms, and the CCIM Institute directly and all confirm that the level of broker participation in CRE transactions as principals is high.
} 


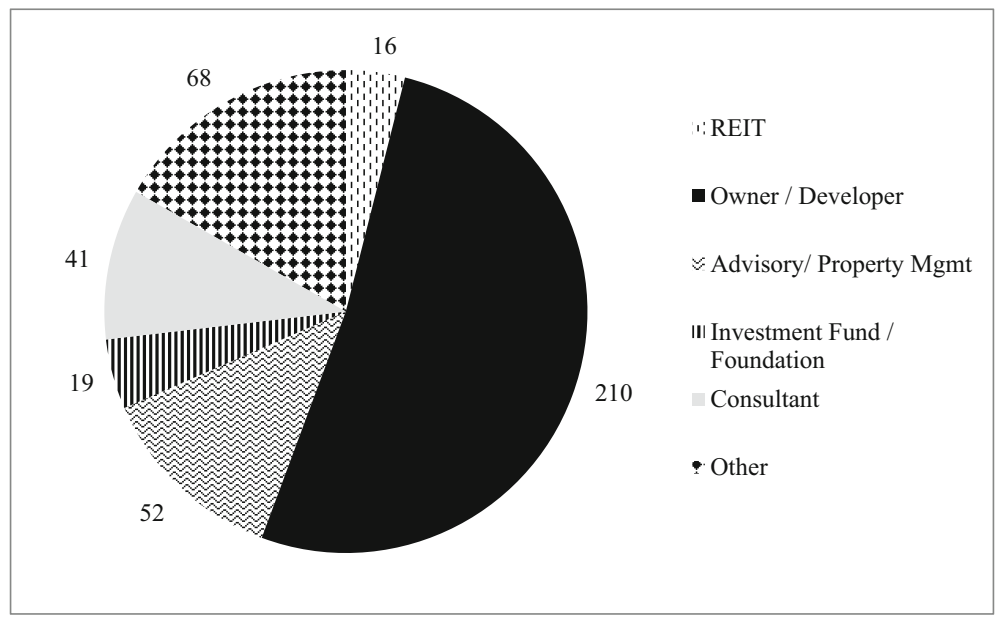

Fig. 1 Organization Description. This figure details the organization with which the participants in the study work. The majority of participants are shown to be owner/developers with the remaining distributed among various institutional and consulting categories

The second part of the experiment maintains an identical setup, except in this scenario the buyer is "quietly informed by a broker, who is a close friend," in a private manner that a specific price should meet the seller's pricing threshold to sell the asset. As defined earlier, this is commonly referred to in the CRE transaction market as a broker whisper price. The proposed guidance numbers are identical to the initial description.

In order to ensure no confounding effects embedded in the setup affect outcomes, a control question is also included where the sentence(s) on "broker guidance" are removed leaving only background, market, and property information.

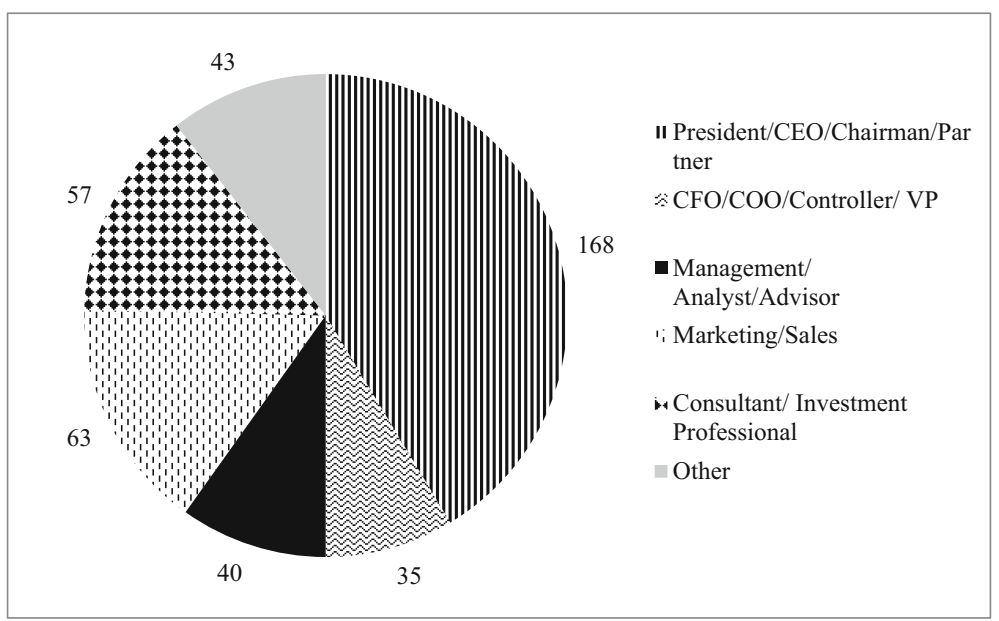

Fig. 2 Job Title Description. This figure details the functional role (i.e., job title description) within an organization for each of the participants in the study. The largest group of participants identifies as President/ $\mathrm{CEO} /$ Chairman/Partner roles and fully half would be decision making levels of Vice President (VP) or higher 


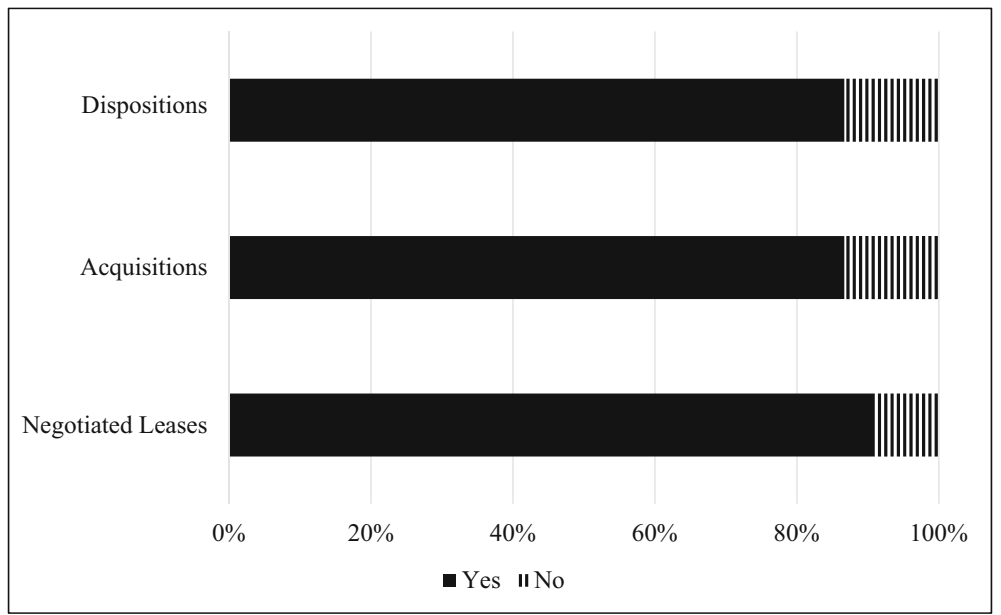

Fig. 3 Experience of Respondents. This figure details the experience with disposition, acquisition, and lease negotiation for each of the participants in the study. Subjects are asked whether or not they have been involved with each of the categories in the past. In every instance, the preponderance of participants demonstrate strong market experience

Sample questions of both broad market signal and broker whisper price are conveyed below; certain phrases are bolded and italicized here for reader emphasis, but are presented as ordinary text in the actual experiment:

Background A 97\% leased, grocery-anchored shopping center is being marketed for sale. Asset details are as follows:

- Anchored by area's dominant grocer with sales in the top $10 \%$ of the chain.

- Inline tenant revenue as a percentage of total property revenue is appropriate, with tenants viewed as healthy.

- Tenant rollover is limited.

- In-place rents are currently at market.

- Year $1 \mathrm{NOI}$ is underwritten at \$2.6 M.

Market Signal Your initial round bid was $\$ 48.6 \mathrm{M}$, a 5.35\% cap rate, which moves you to the Best and Final round. Prior to Best and Final bids, broker guidance of $(\$ 49.5 \mathrm{M} / \$ 52.0 \mathrm{M} / \$ 54.7 \mathrm{M})$ is given to all bidders, an $\mathrm{X} \%$ cap rate. ${ }^{7}$ Recent transactions of similar properties have traded at a $5.00 \%$ cap rate. What price would you submit for your Best \& Final bid? ${ }^{8}$

or

Privately Communicated Signal from Reliable Source (Broker Whisper) Your initial round bid was $\$ 48.6 \mathrm{M}$, a $5.35 \%$ cap rate, which moves you to the Best and

\footnotetext{
${ }^{7}$ Our software automatically populates "X," the cap rate, depending on the exact treatment to which the subject was randomly assigned.

${ }^{8}$ Similarly, our software calculates in real time the cap rate that corresponds to the price the respondent enters as they type their answer.
} 
Final round. Prior to Best and Final bids, the broker, who is a close friend, has quietly indicated to you that a bid of $(\$ 49.5 \mathrm{M} / \$ 52.0 \mathrm{M} / \$ 54.7 \mathrm{M})$ would win the business. This bid equates to an X\% cap rate. Recent transactions of similar properties have traded at a $5.00 \%$ cap rate. What price would you submit for your Best \& Final bid? ${ }^{9}$

As previously mentioned, the experiment randomizes the signal level. Table 1 presents the breakdown of the different signals provided within the first experiment.

The second experiment focuses on seller behavior. To assess whether certainty of close relates to an illiquidity premium and the degree to which it may be, the experiment constructs a scenario where the seller compares two bidders. The seller is informed they have a bid of $\$ 50,000,000$ from a reliable and known institutional buyer with a higher certainty of close; they are asked how much they would require from a buyer with lesser certainty of close to accept this second bid. Specifically, the participant is informed that the potential buyer has "decent" references, but that your firm has never done business with them before. The design set up for the second experiment examining certainty of close is shown here:

Scenario You are responsible for the disposition of a core asset within your company's portfolio. Your broker has identified 2 lead bidders.

Bidder \#1 - Institutional investor with prior transaction experience with your firm and multiple capital sources for the investment. Surety of close is high.

Bidder \#2 - Private investor with no prior transaction experience with your firm, but decent references. There is some uncertainty on available capital for the investment despite assurances. Surety of close is moderate to low.

The institutional investor's final bid is $\$ 50 \mathrm{M}$. What bid price is necessary for you to pick the private investor?

The construction of the scenario is designed to generate some concern over the likelihood of the sale closing relative to the institutional buyer, but to simultaneously create a real world framing where the potential buyer should be considered a viable option.

A standard Kruskal-Wallis test for difference in means is used to examine statistical differences in the sample (Kruskal and Wallis 1952). This one-way analysis of variance permits effective testing for differences between the expected (control) population and the observed results from the different scenarios. In addition to differences in means tests, regressions are used to estimate differences in seller type.

\section{Results}

Table 2 shows results for the initial signaling tests examining H1 (a and b). The table shows whether bids proposed by the subjects for the property are over, equal, or under expected price, given at $\$ 52,000,000$. The control question, providing only information regarding recent comparable sales and the bid price which was required to be invited into the best and final round, yields below expected price bids $58 \%$ of the time based on comparables. Twenty-seven percent of the control respondents bid exactly at the

\footnotetext{
${ }^{9}$ Again, the cap rate is provided synchronously as the subject types in his answer.
} 
Table 1 Sample size by signal type and guidance level

\begin{tabular}{lllll}
\hline & $\begin{array}{l}\text { Guidance of } \\
\$ 49,500,000\end{array}$ & $\begin{array}{l}\text { Guidance of } \\
\$ 52,000,000\end{array}$ & $\begin{array}{l}\text { Guidance of } \\
\$ 54,700,000\end{array}$ & $\begin{array}{l}\text { No Guidance/ } \\
\text { Control }\end{array}$ \\
\hline $\begin{array}{l}\text { Market Signal } \\
\begin{array}{l}\text { Private Signal from a } \\
\text { Reliable Source }\end{array}\end{array}$ & 62 & 71 & 62 & $\mathrm{n} / \mathrm{a}$ \\
$\begin{array}{l}\text { Total } \\
\text { Tota }\end{array}$ & 122 & 87 & 84 & $\mathrm{n} / \mathrm{a}$ \\
\hline
\end{tabular}

This table represents the sample size of each signal type and guidance level randomly generated in the experiment. Participants are told they have previously put forth an initial bid of $\$ 48,600,000$, which has moved them into the best and final round of bidding. The question provides information regarding current market transactions which are reported to trade at a $5.0 \%$ capitalization rate or $\$ 52,000,000$ based on the provided NOI of $\$ 2,600,000$. Questions are randomly generated into one of two broad scenarios. Participants are either informed that broker guidance of $(\$ 49,500,000 / \$ 52,000,000 / \$ 54,700,000)$ is given to all bidders, defined in the table as Market Signal, or that the broker, who is a close friend, has quietly indicated that a bid of $(\$ 49,500,000 / \$ 52,000,000 / \$ 54,700,000)$ would win the business, defined as a Private Signal from a Reliable Source. A control question is also included where the participant receives no further guidance other than the general market information

expected price, while $16 \%$ are aggressive bidders, valuing the property over recent comparable transactions.

Overall, results of these two-way tests show statistically significant differences in all above- and below-expected bids relative to the control set when those signals are provided. A statistically significant percentage are more willing to submit a bid higher than the expected price when provided with a signal over the reference point, and

Table 2 Analysis of first experiment, bid differences by signal level

\begin{tabular}{lllll}
\hline & $\begin{array}{l}\text { Guidance of } \\
\$ 49,500,000\end{array}$ & $\begin{array}{l}\text { Guidance of } \\
\$ 52,000,000\end{array}$ & $\begin{array}{l}\text { Guidance of } \\
\$ 54,700,000\end{array}$ & $\begin{array}{l}\text { No Guidance/ } \\
\text { Control }\end{array}$ \\
\hline Respondent Bid Over Expected Price & $2 \% * * *$ & $16 \%$ & $42 \% * * *$ & $16 \%$ \\
Different from Control & $p \leq 0.0002$ & $p \leq 0.9708$ & $p \leq 0.0003$ & \\
Respondent Bid Equal to Expected Price & $15 \% * *$ & $30 \%$ & $38 \%$ & $27 \%$ \\
Different from Control & $p \leq 0.0492$ & $p \leq 0.6359$ & $p \leq 0.1282$ & \\
Respondent Bid Under Expected Price & $83 \% * *$ & $54 \%$ & $20 \% * * *$ & $58 \%$ \\
Different from Control & $p \leq 0.0001$ & $p \leq 0.6468$ & $p \leq 0.0001$ & \\
Total & 146 & 158 & 122 & 64 \\
\hline
\end{tabular}

This table reports analysis on the first experiment. Participants are told they have previously put forth an initial bid of $\$ 48,600,000$, which has moved them into the best and final round of bidding. The question provides information regarding current market transactions which are reported to trade at a $5.0 \%$ capitalization rate or $\$ 52,000,000$ based on the provided NOI of $\$ 2,600,000$. Questions are randomly generated to provide a signal that a bid of $(\$ 49,500,000 / \$ 52,000,000 / \$ 54,700,000)$ should win the property. This table does not differentiate on the strength of the signal provided. A control question is also included where the participant receives no further guidance other than the general market information. The table tests for differences in the percentage of participants whose bid price is over, under, or equal to the expected price suggested by the recent transactions outlined in the experiment as compared to the same percentages in the control question

$* * * p<0.01, * * p<0.05$ 
correspondingly fewer submit a bid below the expected price in this situation. Similarly, and with even greater power, more participants place a below expectation bid with corresponding guidance, and virtually no one submits an above expectation bid in that scenario.

Questions where selling brokers inform buyer representation that a $\$ 54,700,000$ bid is needed clearly moves observed bids. $42 \%$ of respondents bid over the expected price, statistically different from the control group at a $1 \%$ significance level. Only $20 \%$ still try to bid under the expected price, also significantly different from the control.

When a price of $\$ 52,000,000$, exactly in line with comparable transactions or expected price, is given as guidance, no impact is shown relative to the control group. None of the categories are statistically different from the control. It appears that, without additional information, bidders are likely to bid at or near the expected price. This information validates the control column as statistically meaningful and an appropriate baseline upon which to compare the other reference points.

When guidance that a below expected price bid, $\$ 49,500,000$, should be sufficient to purchase the property is provided, the observed bid is again moved. Fully $83 \%$ of the respondents now bid under the expected price as determined by comparables. This is statistically different from the control at a $1 \%$ significance level. In this case, and different from the over expected price bid, even those willing to move up to only the expected price is lower and statistically different from the control. Virtually none of the respondents bid over the expected price, statistically different at a $1 \%$ level of significance from the control.

It appears broker signaling is able to influence pricing outcomes, but even more so with the potential of a perceived bargain. Both of the first two hypotheses are shown as statistically likely, with greater power for an under expectation signal. The subsequent analysis provides additional insight into the signaling mechanism.

The second set of hypotheses concerns the strength of a broker signal relative to its public versus private source. Table 3 shows results from two-way tests in differences between treatments where guidance is provided by "a broker to everyone" versus a broker whisper price quietly communicated by a "broker who is a close friend." Raw results ostensibly show that the private signal moves the observed bid upwards relative to a public signal. However, due to randomization in the experiment, the number of observations executed at each of the signal levels is unequal. To account for this difference, the bids are adjusted for the signal provided by subtracting it from the bid. Thus, a bid of $\$ 54,700,000$ with a signal of $\$ 54,700,000$ is set to $\$ 0$ with a range surrounding it. After adjusting the scores, effectively isolating within question volatility, the results show no statistical differences across the whole sample between private versus public signals. Similarly, after controlling for guidance, neither the public nor private signals are statistically different from the control.

However, more interesting results appear when examining differences between the reliable private signal, or broker whisper price, and the public signal at each of the different signal levels. Only when attempting to increase a price beyond that which is expected does the strength of the signal reveal a statistically significant difference. This could be partially explained by the market perception of the broker's motivation. When proposing lower or at expectation guidance, certainty of close is the likely motive; which is further examined in the next experiment. When the selling broker proposes a higher clear price, a buyer who does not know the selling broker may assume the 
Table 3 Analysis of first experiment, differences by signal strength

\begin{tabular}{lll}
\hline Comparison Category & $\begin{array}{l}\text { Prob }>\text { Chi-Square } \\
\text { Raw Scores }\end{array}$ & Adjusted for Target \\
\hline Market Signal vs. Private Signal--all questions & $0.0171^{* *}$ & 0.8927 \\
Market Signal vs. Control & 0.0969 & 0.2517 \\
Private Signal vs. Control & 0.9606 & 0.1795 \\
Market Signal vs. Private Signal \$49.5MM Guidance & 0.9790 & \\
Market Signal vs. Private Signal \$52.0MM Guidance & 0.3788 & \\
Market Signal vs. Private Signal \$54.7MM Guidance & $<0.0001 * * *$ & \\
\hline
\end{tabular}

This table reports analysis on the first experiment. Participants are told they have previously put forth an initial bid of $\$ 48,600,000$, which has moved them into the best and final round of bidding. The question provides information regarding current market transactions which are reported to trade at a $5.0 \%$ capitalization rate or $\$ 52,000,000$ based on the provided NOI of $\$ 2,600,000$. Questions are randomly generated into one of two broad scenarios. Participants are either informed that broker guidance of $(\$ 49,500,000 / \$ 52,000,000 /$ $\$ 54,700,000)$ is given to all bidders, defined in the table as Market Signal, or that the broker, who is a close friend, has quietly indicated that a bid of $(\$ 49,500,000 / \$ 52,000,000 / \$ 54,700,000)$ would win the property, defined as a Private Signal from Reliable Source. This table shows results from tests on whether respondents are influenced differently by guidance from a broad market signal or a privately communicated signal from a reliable source. Raw scores do not include adjustments for guidance and test the entire data set. Adjusted for Target scores normalize the response by the proposed broker guidance i.e. a bid of $\$ 54,700,000$ where that guidance is set to zero with a range around it. Where guidance levels between market and private signals are identical, no adjustment is required. Tests are difference of means between the described samples

$* * * p<0.01, * * p<0.05$

broker is maximizing value for the seller or acting in the broker's self-interest. However, when the signal comes from a "close friend," the motivation may be genuinely beneficial to the buyer. The results suggest $\mathrm{H} 2 \mathrm{a}$ is not confirmed; a signal for below expected price is equally received regardless of its source. However, H2b is confirmed, at a $1 \%$ significance level that signals above expected prices are stronger when coming from a reliable source.

This set of results suggests that relationships matter in CRE transactions. Signaling the likely sale price has greater strength when it comes from someone deemed to be a close friend. In other words, brokers with established relationships of trust are more likely to persuade buyers that the likely sale price of the asset exceeds that of similar properties. In reality, property value is always a range as acquisition pricing is forward looking while comparable prices are backward looking. However, the experiment effectively isolates the broker's input as no other information concerning the buyer's capital needs or market direction is given. Thus, the signaling effect is successfully demonstrated.

Results from testing the third hypothesis are reported in Table 4. With a median bid of $\$ 55,000,000$ (and the same bid at the 75th quartile) the results clearly suggest that certainty of close is considered by market participants to have value. The mean price at which sellers would accept a second bid with lesser certainty of close is $\$ 54,561,526$, statistically different than a bid with higher certainty at a $1 \%$ significance level. The data reveal an approximately $10 \%$ premium for a buyer with lesser certainty of close. Due to the illiquid nature of real estate, potential 1031 up-leg sale factors, holding costs 
Table 4 Analysis of second experiment, descriptive statistics and difference in mean

Required Bid Amount

Mean

$\$ 54,561,526 * * *$

75th Percentile

$\$ 55,000,000$

Median

$\$ 55,000,000$

25th percentile

$\$ 52,500,000$

This table reports descriptive statistics on the second experiment. A seller is informed they have a bid of $\$ 50,000,000$ from a reliable and known institutional buyer with a higher certainty of close; they are asked how much they would require from a buyer with lesser certainty of close to accept this second bid. The test determines whether the mean is different from a competing bid of $\$ 50,000,000$

$* * * p<0.01$

and other issues typically experienced in practice, the finding for a premium is not surprising. To the best of our knowledge, this is the first academic finding directly supporting surety of close as a defined premium (discount) in the market. The third hypothesis, that sellers extract a premium for greater execution risk is confirmed at a $1 \%$ significance level. The data reveal that certainty of close is a considerable risk factor with an economically relevant risk premium associated with it.

The fourth hypothesis is examined in Table 5 via regression analysis of the different seller types. No difference is found for a buyer among institutional, advisory, and owner/developer (omitted) firms regarding their response to signaling effects in the purchase of a property. However, the value placed on certainty of close shows statistically different responses among seller types. Institutional investors demonstrate a lower risk aversion than owner/developers; advisory firms are likely employed by institutional investors and show a similar result. In addition to its statistical significance,

Table 5 Regression analysis for the first and second experiments

\begin{tabular}{|c|c|c|c|c|c|c|}
\hline \multirow[t]{2}{*}{ Parameter } & \multicolumn{3}{|c|}{$\begin{array}{l}\text { Dependent Variable Difference } \\
\text { from Signal }\end{array}$} & \multicolumn{3}{|c|}{$\begin{array}{l}\text { Dependent Variable Required Bid from buyer with } \\
\text { less certainty of close than one who offered } \\
\$ 50,000,000\end{array}$} \\
\hline & Estimate & t-statistic & Prob. & Estimate & t-statistic & Prob. \\
\hline Intercept & $-906,107$ & -7.56 & $<0.0001$ & $55,082,250$ & 208.40 & $<0.0001$ \\
\hline Advisory Firm & $-227,832$ & -1.25 & 0.2136 & $-802,871 * *$ & -2.13 & 0.0341 \\
\hline Institutional Firm & $-195,281$ & -0.56 & 0.5761 & $-1,940,144^{* * * *}$ & -2.96 & 0.0033 \\
\hline Observations & 394 & & & 385 & & \\
\hline
\end{tabular}

This table reports regression analysis on both experiments. In the first experiment, participants are told they have previously put forth an initial bid of $\$ 48,600,000$, which has moved them into the best and final round of bidding. The question provides information regarding recent transactions which are reported to trade at a $5.0 \%$ capitalization rate or $\$ 52,000,000$ based on the provided NOI of $\$ 2,600,000$. Questions are randomly generated to provide a signal that a bid of $(\$ 49,500,000 / \$ 52,000,000 / \$ 54,700,000)$ should win the property. In the second experiment, a seller is informed they have a bid of $\$ 50,000,000$ from a reliable and known institutional buyer with a higher certainty of close; they are asked how much they would require from a buyer with lesser certainty of close to accept this second bid. This table reports for differences between firms that are advisory firms, institutional firms and owner/developer firms (omitted)

$* * * p<0.01, * * p<0.05$ 
the coefficient is also economically significant at nearly $\$ 2,000,000$, or $4.0 \%$ of price. A number of possible explanations exist. There could be differences in typical buyer profiles and asset composition for institutional investors. Institutional investors may hold a greater percentage of blue chip assets that tend to cash flow during a holding period, reducing the closing risk. Furthermore, some investors may be less cash constrained with a lower likelihood of a sale affecting a near term purchase. While the exact motivations are left for future research, the results do show a statistically significantly lower value placed on certainty of close with institutional investors.

\section{Conclusions}

This study uses behavioral experiments to test for the effects of signaling and uncertainty in commercial real estate transactions, using a rich and meaningful sample of certified commercial investment member designees and candidates. The sample includes decision makers whose CCIM designation or candidacy implies above average knowledge of real estate markets. The results reveal clear signaling effects with demonstrated differences in price movement based on signal reliability. This is particularly evident when the signal is for a price above that which is expected based on comparable prices. While any type of signal that a bargain may be available resonates, the broker whisper price, or quietly communicated private signal, is the only signal that will move the transaction price over comparable sales at a statistically significant level. This evidence supports a "true market price" signal as in Bokhari and Geltner (2011), particularly when the signal is reliable.

Furthermore, the paper examines certainty of close. The results reveal clear evidence that a lower certainty of close can command an approximately $10 \%$ price premium required for a buyer with uncertain closing capabilities. As compared to owner/developers, institutional investors demonstrate a lower propensity for this premium at statistically and economically significant levels.

This paper contributes to the literature in a number of ways. First, it advances the discussion around CRE brokerage demonstrating that specific broker behaviors can influence price. It documents signaling effects and provides evidence that the strength of the signal directly affects the outcome in certain instances. The results show that certainty of close is a risk in CRE, and that a price premium is associated with it. Furthermore, the results reveal that institutional investors consider certainty of close to be of lesser risk, but that a statistically significant premium remains at approximately $6.0 \%$.

\section{References}

An, X., Deng, Y., Fisher, J. D., \& Hu, M. R. (2015). Commercial real estate rental index: a dynamic panel data model estimation. Real Estate Economics, 44(2), 378-410.

Anglin, P. M., \& Gao, Y. (2011). Integrating illiquid assets into the portfolio decision process. Real Estate Economics, 39(2), 277-311.

Barwick, P.J., Pathak, P.A., \& Wong, M. (2016). Conflicts of interest and steering in residential brokerage. American Economic Journal: Applied Economics. Forthcoming. 
Benefield, J., Pyles, M., \& Gleason, A. (2011). Sale price, marketing time, and limited service listings: the influence of home value and market conditions. Journal of Real Estate Research, 33(4), 531-563.

Benjamin, J. D., Chinloy, P., \& Jud, G. D. (2004). Real estate versus financial wealth in consumption. Journal of Real Estate Finance and Economics, 29(3), 341-354.

Beracha, E., \& Seiler, M. J. (2014). The effect of listing price strategy on transaction selling prices. Journal of Real Estate Finance and Economics, 49(2), 237-255.

Bernheim, B.D., \& Meer, J. (2008). How much value do real estate brokers add? A case study. Working Paper, National Bureau of Economic Research.

Bian, X., Turnbull, G. K., \& Waller, B. D. (2017). Client externality effects of agents selling their own properties. Journal of Real Estate Finance and Economics, 54(2), 139-164.

Bokhari, S., \& Geltner, D. (2011). Loss aversion and anchoring in commercial real estate pricing: Empirical evidence and price index implications. Real Estate Economics, 39(4), 635-670.

Bond, S. A., Hwang, S., Lin, Z., \& Vandell, K. D. (2007). Marketing period risk in a portfolio context: Theory and empirical estimates from the UK commercial real estate market. Journal of Real Estate Finance and Economics, 34(4), 447-461.

Brastow, R. T., Springer, T. M., \& Waller, B. D. (2012). Efficiency and incentives in residential brokerage. Journal of Real Estate Finance and Economics, 45(4), 1041-1061.

Cheng, P., Lin, Z., \& Liu, Y. (2008). A model of time on market and real estate price under sequential search with recall. Real Estate Economics, 36(4), 813-843.

Chinloy, P., Hardin III, W., \& Wu, Z. (2013). Price, Place, People, and Local Experience. Journal of Real Estate Research, 35(4), 477-505.

D'Lima, W. (2016). Optimal compensation and value added in commercial real estate brokerage. Working Paper, University of Notre Dame.

Daneshvary, N., \& Clauretie, T. M. (2013). Agent change and seller bargaining power: a case of principal agent problem in the housing market. Journal of Real Estate Finance and Economics, 47(3), 416-433.

Devaney, S., \& Scofield, D. (2013). Broker use and the cost of liquidity in commercial real estate investment. Journal of European Real Estate Research, 6(3), 279-302.

Devaney, S., \& Scofield, D. (2015). Liquidity and the drivers of search, due diligence and transaction times for UK commercial real estate investments. Journal of Property Research, 32(4), 362-383.

Devaney, S., \& Scofield, D. (2017). Do 'foreigners' pay more? The effects of investor type and nationality on office transaction prices in New York City. Journal of Property Research, 34(1), 1-18.

Dhar, R., \& Goetzmann, W.N. (2005). Institutional perspectives on real estate investing: The role of risk and uncertainty. Working Paper, Yale University.

Elder, H. W., Zumpano, L. V., \& Baryla, E. A. (1999). Buyer search intensity and the role of the residential real estate broker. Journal of Real Estate Finance and Economics, 18(3), 351-368.

Elder, H. W., Zumpano, L. V., \& Baryla, E. A. (2000). Buyer brokers: Do they make a difference? Their influence on selling price and search duration. Real Estate Economics, 28(2), 337-362.

Garmaise, M. J., \& Moskowitz, T. J. (2004). Confronting information asymmetries: Evidence from real estate markets. Review of Financial Studies, 17(2), 405-437.

Gatzlaff, D. H., \& Liu, P. (2013). List price information in the negotiation of commercial real estate transactions: Is silence golden? Journal of Real Estate Finance and Economics, 47(4), 760-786.

Goodwin, K. R., Johnson, K. H., \& Zumpano, L. V. (2012). Minimum service requirements, limited brokers and menuing of services. Journal of Real Estate Finance and Economics, 45(2), 471-490.

Haigh, M. S., \& List, J. A. (2005). Do professional traders exhibit myopic loss aversion? An experimental analysis. Journal of Finance, 60(1), 523-534.

Han, L., \& Hong, S. H. (2016). Understanding in house transactions in the real estate brokerage industry. RAND Journal of Economics, 47(4), 1057-1086.

Hardin III, W., Johnson, K. H., \& Wu, Z. (2009). Brokerage intermediation in the commercial property market. Journal of Real Estate Research, 31(4), 397-420.

Hendel, I., Nevo, A., \& Ortalo-Magné, F. (2009). The relative performance of real estate marketing platforms: MLS versus FSBOMadison. com. American Economic Review, 99(5), 1878-1898.

Hsieh, C. T., \& Moretti, E. (2003). Can free entry be inefficient? Fixed commissions and social waste in the real estate industry. Journal of Political Economy, 111(5), 1076-1122.

Johnson, K. H., Wiley, J., \& Florida, Z. (2007). On the relationship between commercial property price and its selling time. Journal of Real Estate Portfolio Management, 13(4), 379-388.

Johnson, K. H., Lin, Z., \& Xie, J. (2015). Dual agent distortions in real estate transactions. Real Estate Economics, 43(2), 507-536.

Kadiyali, V., Prince, J., \& Simon, D. H. (2014). Is dual agency in real estate a cause for concern? Journal of Real Estate Finance and Economics, 48(1), 164-195. 
Korngold, G. (2011). Real estate brokers are not 'fiduciaries': A call for developing a new legal framework. Real Estate Law Journal, 40(3), 376-391.

Kruskal, W. H., \& Wallis, W. A. (1952). Use of ranks in one-criterion variance analysis. Journal of the American Statistical Association, 47(260), 583-621.

Lambson, V. E., McQueen, G. R., \& Slade, B. A. (2004). Do out of state buyers pay more for real estate? An examination of anchoring induced bias and search costs. Real Estate Economics, 32(1), 85-126.

Levitt, S. D., \& Syverson, C. (2008). Market distortions when agents are better informed: The value of information in real estate transactions. Review of Economics and Statistics, 90(4), 599-611.

Lin, Z., Liu, Y., \& Vandell, K. D. (2009). Marketing period risk in a portfolio context: Comment and extension. Journal of Real Estate Finance and Economics, 38(2), 183-191.

Lin, Z., \& Vandell, K. D. (2007). Illiquidity and pricing biases in the real estate market. Real Estate Economics, 35(3), 291-330.

Ling, D. C., Naranjo, A., \& Petrova, M. T. (2016). Search costs, behavioral biases, and information intermediary effects. Journal of Real Estate Finance and Economics, 1-38.

McAllister, P., Hughes, C., \& Gallimore, P. (2008). Principal agent issues in asset acquisition: UK institutions and their investment agents. Journal of Property Research, 25(4), 269-283.

Munneke, H. J., Ooi, J. T., Sirmans, C. F., \& Turnbull, G. K. (2011). Sequential sales of similar assets: The law of one price and real estate. Journal of Regional Science, 51(2), 355-370.

Munneke, H. J., \& Yavas, A. (2001). Incentives and performance in real estate brokerage. Journal of Real Estate Finance and Economics, 22(1), 5-21.

Scofield, D. (2013). Time to completion liquidity in UK commercial real estate investment: 2000-2008. Journal of European Real Estate Research, 6(1), 34- 47.

Seiler, M. J. (2014). Behavioral Real Estate. In H. K. Baker \& P. Chinloy (Eds.), Private real estate markets and investments. Oxford UK: Oxford University Press.

Shy, O. (2012). Real estate brokers and commission: Theory and calibrations. Journal of Real Estate Finance and Economics, 45(4), 982-1004.

Turnbull, G. K., \& Dombrow, J. (2007). Individual agents, firms, and the real estate brokerage process. Journal of Real Estate Finance and Economics, 35(1), 57-76.

Vandell, K. D. (2007). Expanding the academic discipline of real estate valuation: A historical perspective with implications for the future. Journal of Property Investment \& Finance, 25(5), 427-443.

Wiley, J. A., Benefield, J. D., \& Allen, M. T. (2014). Cyclical determinants of brokerage commission rates. Journal of Real Estate Finance and Economics, 48(1), 196-219.

Zietz, E. N., \& Sirmans, G. S. (2011). Real estate brokerage research in the new millennium. Journal of Real Estate Literature, 19(1), 5-40. 